\title{
ĐÁNH GIÁ KHẢ NĂNG SẢN XUẤT MELAMINE TỪ NGUỒN NGUYÊN LIẸU DİCH UREA CỦA NHÀ MÁY ĐẠM CÀ MAU
}

\author{
Võ Thị Thương, Trần Vĩnh Lộc, Lê Dương Hải, Nguyễn Thị Mai Lê, Phạm Thu Trang, Nguyễn Trung Đức \\ Nguyễn Mạnh Huấn, Nguyễn Ánh Thu Hằng, Huỳnh Minh Thuận \\ Viện Dầu khí Việt Nam \\ Email: thuongvt.pvpro@vpi.pvn.vn \\ https://doi.org/10.47800/PVJ.2021.04-04
}

\section{Tóm tắt}

Bài báo phân tích cơ hội đầu tư dự án sản xuất melamine từnguồn urea của Nhà máy Đạm Cà Mau dựa trên các yếu tố nguyên liệu, thị trường, công nghệ và hiệu quả kinh tế. Việt Nam nhập khẩu melamine để đáp ứng nhu cầu trong nước được dự báo khoảng 40 nghìn tấn/ năm vào năm 2025 và sau đó tiếp tục tăng trưởng khoảng 5,5\%/năm. Dự án đầu tư sản xuất melamine từ nguồn urea của Nhà máy Đạm Cà Mau với quy mô công suất 40 nghìn tấn/năm, dự kiến đi vào vận hành vào năm 2027. Kết quả tính toán cho thấy, với tổng mức đầu tư (bao gồm thuế, lãi vay và vốn lưu động năm đầu) khoảng 6.308 tỷ đồng, dự án cho kết quả IRR khoảng 17,2\% và NPV@10\% là 1.884 tỷ đồng; tổng thời gian thu hồi vốn là 5 năm và 9 tháng. Do đó, melamine có thể coi là sản phẩm tiềm năng để xem xét đầu tư trong thời gian tới.

Tù khóa: Melamine, urea, đa dạng hóa sản phẩm, Nhà máy Đạm Cà Mau.

\section{Giới thiệu}

Melamine được sử dụng trong công nghiệp như: sản xuất keo dán, chất phủ bề mặt, sản xuất nhựa melamine formaldehyde, sản xuất giấy và lốp xe. Năm 2017, toàn thế giới tiêu thụ khoảng 1,75 triệu tấn melamine và hơn $70 \%$ tổng tiêu thụ được sử dụng làm nguyên liệu để sản xuất các sản phẩm keo dán gỗ và laminate. Keo dán gỗ được sử dụng trong công nghiệp sản xuất các loại gỗ, ván dăm và ván ép. Melamine trong keo dán gỗ giúp cải thiện độ bền và khả năng chống ẩm cho gỗ thành phẩm. Laminate được sử dụng trong các sản phẩm như đồ gia dụng, tủ bếp, vật dụng nhà bếp, sàn nhà và tường gỗ [1]. Công nghệ sản xuất melamine tích hợp với nhà máy sản xuất phân bón đã được nghiên cứu phát triển và chứng minh được hiệu quả tại các nhà máy thương mại trên thế giới $[2,3]$. Việc tích hợp sản xuất melamine với nhà máy sản xuất urea cho phép hồi lưu các dòng thải từ xưởng melamine về làm nguyên liệu cho nhà máy urea. Sản phẩm urea sau đó được cung cấp làm nguyên liệu cho nhà máy sản xuất melamine, do đó giúp giảm lượng tiêu hao riêng của nguyên liệu urea, chỉ còn khoảng 1,4 1,5 tấn urea/tấn melamine (giảm 2 lần so với xây dựng các nhà máy riêng lẻ) [4].

Ngày nhận bài: 02/12/2020. Ngày phản biện đánh giá và sửa chữa:02/12/2020 - 28/2/2021. Ngày bài báo được duyệt đăng: 1/4/2021.
Về công nghệ sản xuất, melamine có thể được tổng hợp từ 3 nguồn nguyên liệu khác nhau là urea, dicyandiamide và hydrogen cyanide. Trong đó, chỉ có quá trình đi từ urea và dicyandiamide được thương mại hóa. Đặc biệt, quá trình đi từ nguyên liệu urea đang được sử dụng chủ yếu do chi phí sản xuất thấp.

Nhà máy Đạm Cà Mau sau thời gian đi vào hoạt động ổn định, cung cấp ra thị trường hàng năm trên 800 nghìn tấn urea, góp phần đảm bảo an ninh lương thực cho đất nước. Nhà máy Đạm Cà Mau đã sản xuất trên 7 triệu tấn urea sau 10 năm vận hành [5]. Tuy nhiên, việc đưa vào vận hành một số nhà máy đạm trong nước và khu vực gần đây, cùng với sự suy giảm về sản lượng khí và/hoặc thay đổi giá khí đã và sẽ ảnh hưởng đến hoạt động ổn định của nhà máy. Vi vậy, việc xem xét, tìm kiếm giải pháp nhằm nâng cao năng lực cạnh tranh, thích ứng với sự biến động của thị trường của nhà máy là cần thiết. Do đó, Tập đoàn Dầu khí Việt Nam đã giao Viện Dầu khí Việt Nam (VPI) nghiên cứu các giải pháp kỹ thuật công nghệ nhằm nâng cao năng lực cạnh tranh của các nhà máy đạm, trong đó có phương án sản xuất melamine từ nguồn nguyên liệu dịch urea của Nhà máy Đạm Cà Mau. 
Bài báo trình bày kết quả đánh giá sơ bộ khả năng sản xuất melamine từ nguồn nguyên liệu urea dựa trên các tiêu chí về thị trường, kỹ thuật và kinh tế nhằm xem xét khả năng đa dạng hóa sản phẩm, góp phần nâng cao hiệu quả sản xuất kinh doanh của Nhà máy Đạm Cà Mau.

\section{Thị trường nguyên liệu và sản phẩm}

\subsection{Thị trường melamine}

Ở Việt Nam, melamine được sử dụng phổ biến làm nguyên liệu để sản xuất keo dán MUF (melamine urea formaldehyde) sử dụng trong các ngành công nghiệp gỗ ván ép, giày dép, sản xuất chất phủ bề mặt gỗ và sản xuất nhựa melamine formaldehyde. Tỷ trọng của các ứng dụng này chiếm hơn $90 \%$ tổng lượng tiêu thụ melamine nội địa. Một lượng nhỏ melamine được dùng để pha trong dung môi của ngành công nghiệp sơn. Cơ cấu tiêu thụ melamine theo các ứng dụng thể hiện ở Hình 1.

Hiện tại, Việt Nam chưa có nhà máy sản xuất melamine nên phải nhập khẩu hoàn toàn. Giai đoạn

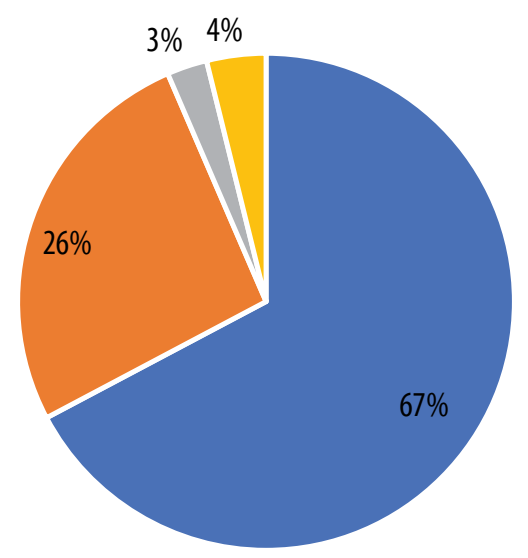

- Keo dán gỗ - Chất phủ bề mặt gỗ - Công nghiệp nhựa —Khác

Hình 1. Tỷ trọng sử dụng melamine tại Việt Nam năm 2018.

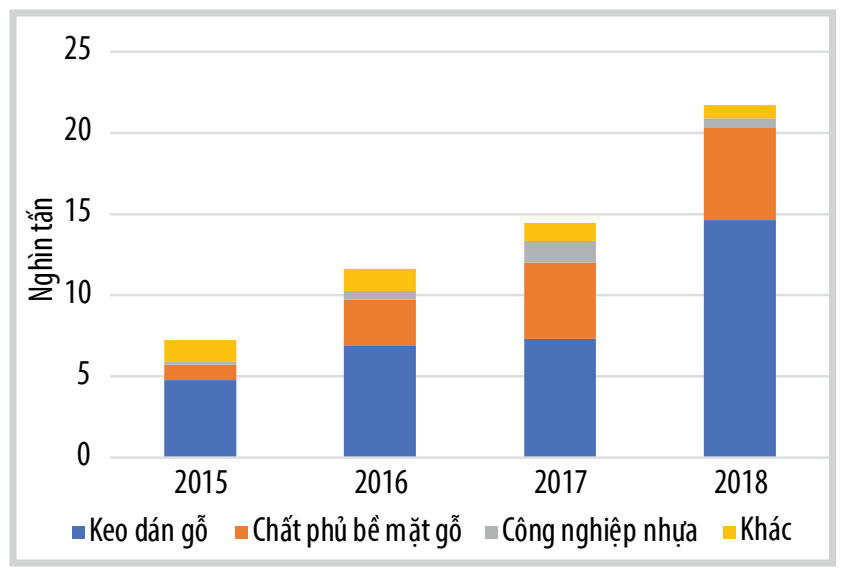

Hình 2. Nhu cầu tiêu thụ melamine của Việt Nam 2015 - 2018. Nguôn: Tổng cục Hải quan, 2019.
2014 - 2018, tốc độ tăng trưởng nhu cầu melamine đạt trung bình 41,3\%/năm. Năm 2016, nhu cầu melamine tăng 60\% so với năm 2015 do tổ hợp VRG Dongwha đi vào hoạt động với tổng công suất $480.000 \mathrm{~m}^{3} /$ năm MDF (medium density fiberboard, ván sợi mật độ trung bình), dẫn đến nhu cầu melamine cho sản xuất keo MUF tăng. Thành phần melamine cho sản xuất keo MUF tùy thuộc vào chủng loại và phẩm cấp keo, thường chiếm khoảng $3 \%$ khối lượng keo [1], tỷ lệ sử dụng keo so với gỗ ván ép dao động khoảng 11 - 13\% khối lượng [6, 7]. Như vậy, với công suất $480.000 \mathrm{~m}^{3} \mathrm{MDF} /$ năm thì nhu cầu ước tính lượng melamine tổ hợp VRG Dongwha cần sử dụng là 1,8 nghìn tấn/năm. Năm 2018, Việt Nam tiêu thụ khoảng 21,7 nghìn tấn melamine (trong đó melamine dạng bột chiếm hơn $80 \%$ ), được nhập khẩu chủ yếu từ Trung Quốc (96,3\%), ngoài ra còn nhập khẩu từ các nước khác như Đài Loan ( $1,7 \%)$, Hồng Kông $(0,8 \%)$, Nhật Bản $(0,7 \%)$ và Hàn Quốc (0,5\%) [8]. Lượng nhập khẩu melamine năm 2018 tăng 50\% so với 2017 là do FSC Việt Nam đưa vào vận hành Nhà máy sản xuất ván ép MDF công suất 400.000 m3 sản phẩm/năm tại Khu công nghiệp Nam Đồng Phú, Bình Phước. Theo số liệu thống kê hải quan, nhập khẩu melamine chủ yếu tập trung ở khu vực miền Nam (54,5\%), tiếp đến là miền Bắc (35,3\%) và miền Trung (10,2\%) [8].

Bảng 1 thể hiện 10 doanh nghiệp nhập khẩu melamine hàng đầu của Việt Nam. Trong đó, các doanh nghiệp lớn nhập khẩu melamine chủ yếu là đơn vị sản xuất gỗ, keo dán và chủ yếu nhập khẩu melamine dạng bột. Đáng lưuý là doanh nghiệp gỗ Dongwha, keo dán AICA, Better Resin có đối tác/công ty mẹ ở nước ngoài sản xuất melamine. Năm 2018, tổng lượng nhập khẩu melamine của các công ty này đạt 7,2 nghìn tấn, chiếm khoảng hơn $30 \%$ so với tổng nhu cầu melamine ở thị trường nội địa.

Dựa theo nhu cầu phát triển của lĩnh vực ứng dụng cuối (quy hoạch phát triển ngành chế biến gỗ, sản lượng gỗ và ván ép) và nhu cầu tăng trưởng melamine trong giai đoạn 2014 - 2018, tốc độ tăng trưởng melamine ở Việt Nam dự báo sẽ tiếp tục tăng khá mạnh vào năm 2021, sau đó sẽ ở mức khoảng 5,5\%/năm trong giai đoạn 2022 - 2040. Chi tiết về dự báo nhu cầu và tốc độ tăng trưởng được trình bày ở Bảng 2.

Theo khảo sát và đánh giá, chưa có dự án sản xuất melamine nào được xem xét triển khai trong tương lai gần. Do đó, dự kiến đến năm 2025, Việt Nam sẽ thiếu hụt khoảng 40 nghìn tấn melamine và tiếp tục thiếu hụt khoảng 52,6 nghìn tấn (2030), 68,7 nghìn tấn (2035) và 89,8 nghìn tấn (2040). 
Bảng 1. Danh sách 10 doanh nghiệp nhập khẩu melamine lớn nhất năm 2018

\begin{tabular}{|c|c|c|c|}
\hline TT & Tên doanh nghiệp & $\begin{array}{c}\text { Kim ngạch nhập khẩu } \\
\text { (USD) }\end{array}$ & $\begin{array}{c}\text { Lượng nhập khẩu } \\
\text { (tấn) }\end{array}$ \\
\hline 1 & Công ty CP gỗ MDF VRG Dongwha & 3.500 .260 & 2.875 \\
\hline 2 & Công ty TNHH AICA Đồng Nai & 3.070 .945 & 2.522 \\
\hline 3 & Công ty CP gỗ MDF VRG Quảng Trị & 2.798 .120 & 2.298 \\
\hline 4 & Công ty TNHH Thuận Hà & 2.732 .093 & 2.244 \\
\hline 5 & Công ty CP Better Resin & 2.199 .322 & 1.806 \\
\hline 6 & Công ty TNHH Hóa keo Kỹ thuật & 1.372 .304 & 1.127 \\
\hline 7 & Công ty TNHH Sản xuất và Thương mại Long Lựu & 517.210 & 425 \\
\hline 8 & Công ty CP gỗ An Cường & 469.000 & 385 \\
\hline 9 & Công ty CP FSC Việt Nam & 376.200 & 309 \\
\hline 10 & $\begin{array}{l}\text { Công ty TNHH Đầu tư Sản xuất và Thương mại } \\
\text { Xuất nhập khẩu Tâm Đức }\end{array}$ & 305.025 & 251 \\
\hline
\end{tabular}

Nguồn: Tổng cuc Hải quan, 2019

Bảng 2. Dự báo nhu cầu tiêu thụ melamine và tốc độ tăng trưởng giai đoạn 2020 - 2040

\begin{tabular}{|c|c|c|c|c|c|c|c|c|c|c|c|c|c|}
\hline Năm & 2020 & 2021 & 2022 & 2023 & 2024 & 2025 & 2026 & 2027 & 2028 & 2029 & 2030 & 2035 & 2040 \\
\hline Nhu cầu (nghìn tấn) & 29,5 & 32,5 & 34,2 & 36,1 & 38,1 & 40,2 & 42,4 & 44,8 & 47,2 & 49,8 & 52,6 & 68,7 & 89,8 \\
\hline $\begin{array}{l}\text { Tốc độ tăng trưởng } \\
\text { (\%/năm) }\end{array}$ & 14,4 & 10,0 & & & & & & 5,5 & & & & & \\
\hline
\end{tabular}

\subsection{Dự báo giá melamine}

Hiện tại thị trường melamine thế giới đang gặp tình trạng dư cung do nguồn bổ sung công suất lớn ở Trung Quốc. Tình trạng dư cung bắt đầu từ những năm 2000 đã làm giảm đáng kể lợi nhuận của các nhà cung cấp melamine bởi giá melamine Trung Quốc hình thành nên giá sàn chuẩn toàn cầu. Một số nền kinh tế lớn ở châu Âu, Mỹ và Ấn Độ phải áp thuế chống bán phá giá (ADDs) đối với sản phẩm melamine của Trung Quốc trong thập kỷ qua.

Giá melamine được cung cấp bởi Nexant, dự báo giá melamine dựa trên giả định việc áp thuế chống bán phá giá (ADDs) tiếp tục được áp dụng đối với sản phẩm melamine Trung Quốc trong giai đoạn dự báo dài hạn. Điều này sẽ hỗ trợ các nhà sản xuất trong khu vực có lợi nhuận biên phù hợp với tỷ suất lợi nhuận lịch sử (trước khi xảy ra tình trạng dư cung do Trung Quốc trở thành nhà xuất khẩu lớn trên thế giới).

Với việc Tây Âu trở thành khu vực nhập khẩu melamine lớn nhất và có chi phí sản xuất cao nhất, trong khi Trung Quốc là nhà xuất khẩu melamine lớn nhất và có chi phí sản xuất thấp nhất, Nexant dự báo giá melamine tại khu vực Đông Nam Á dựa vào sự chênh lệch giá của 2 thị trường chính này (được phản ánh chủ yếu qua chi phí vận chuyển giữa 2 khu vực).

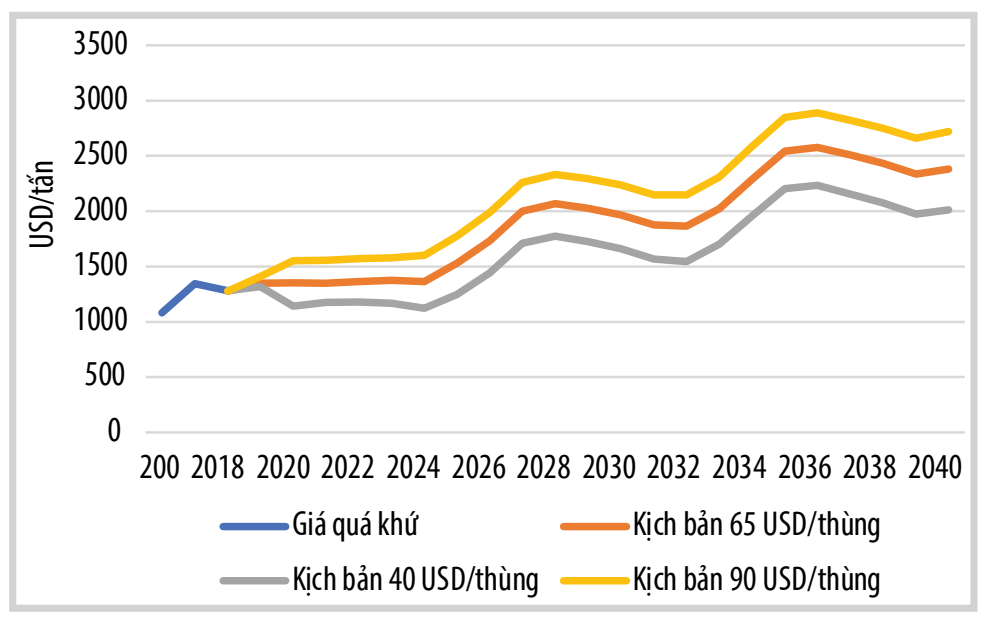

Hình 3. Dự báo giá melamine tại khu vực Đông Nam Á giai đoạn 2009 - 2040. Nguồn: Nexant, 2019.

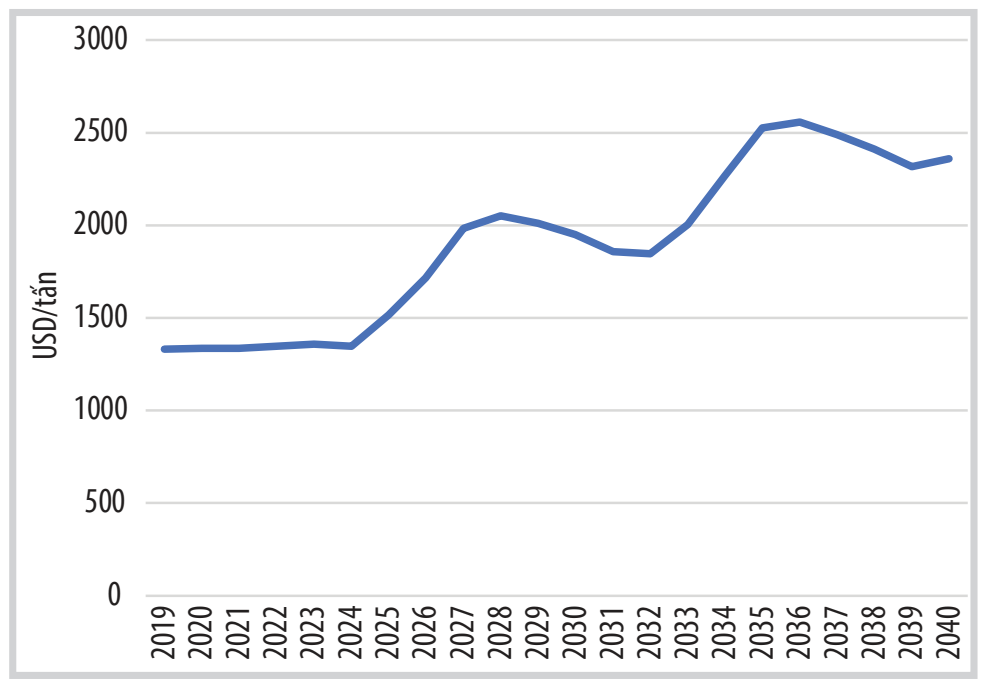

Hình 4. Dự báo giá melamine tại cổng Nhà máy Đạm Cà Mau theo kịch bản giá dâu 65 USD/thùng. 
Bảng 3. Tính chất nguyên liệu dịch urea

\begin{tabular}{|c|c|c|}
\hline TT & Thành phần/tính chất & Giá trị \\
\hline \multirow[t]{6}{*}{1} & Thành phần chính & \\
\hline & $\mathrm{H}_{2} \mathrm{O}$ (\% khối lượng) & 27,48 \\
\hline & $\mathrm{NH}_{3}$ (\% khối lượng) & 1,77 \\
\hline & $\mathrm{CO}_{2}$ (\% khối lượng) & 0,96 \\
\hline & Urea (\% khối lượng) & 69,79 \\
\hline & Biuret (\% khối lượng) & 0,34 \\
\hline \multirow[t]{9}{*}{2} & Tạp chất & \\
\hline & $\mathrm{Ca}(\mathrm{mg} / \mathrm{kg})$ & 1,13 \\
\hline & $\mathrm{Fe}(\mathrm{mg} / \mathrm{kg})$ & $<0,1$ \\
\hline & $\mathrm{Cu}(\mathrm{mg} / \mathrm{kg})$ & $<0,1$ \\
\hline & $\mathrm{Zn}(\mathrm{mg} / \mathrm{kg})$ & $<0,1$ \\
\hline & $\mathrm{Cr}(\mathrm{mg} / \mathrm{kg})$ & $<0,1$ \\
\hline & $\mathrm{Ni}(\mathrm{mg} / \mathrm{kg})$ & $<0,1$ \\
\hline & $\mathrm{Na}(\mathrm{mg} / \mathrm{kg})$ & 0,05 \\
\hline & $\mathrm{K}(\mathrm{mg} / \mathrm{kg})$ & 0,06 \\
\hline 3 & Nhiệt độ ( $\left.{ }^{\circ} \mathrm{C}\right)$ & 147 \\
\hline 4 & Áp suất (MPa) & 0,41 \\
\hline
\end{tabular}

Nguôn: PVCFC

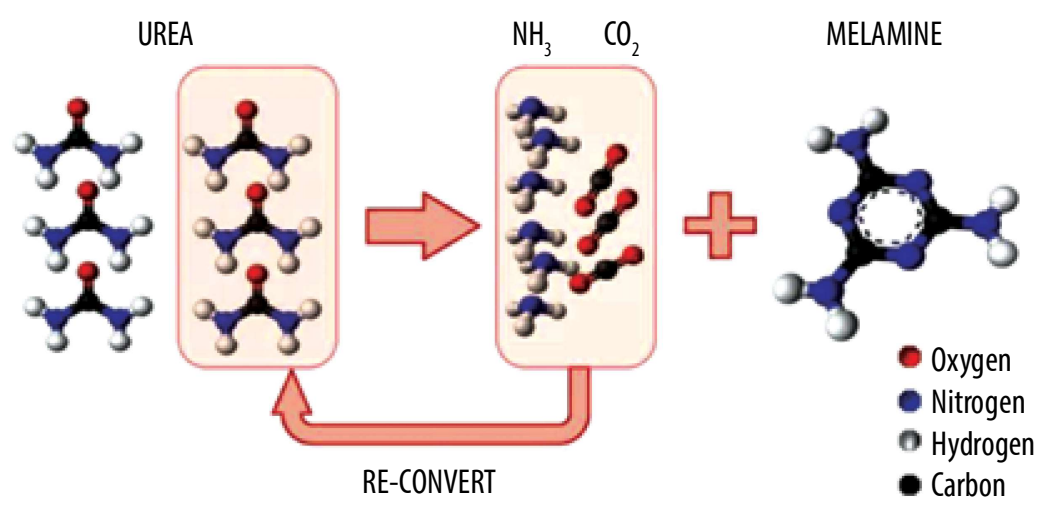

Hình 5. Sơ đô phản ứng quá trình sản xuất melamine tích hợp với sản xuất urea. Nguồn: Eurotecnica, 2020.

Theo đó, giá melamine tại khu vực Đông Nam Á (giá đã bao gồm chi phí vận chuyển) ở mức 1.278 USD/tấn năm 2018. Trong giai đoạn 2019 - 2040, giá melamine dự kiến tăng bình quân 2,9\%/năm. Giá melamine dự kiến ở mức 1.531 USD/tấn (2025), 1.967 USD/tấn (2030), 2.544 USD/ tấn (2035) và 2.382 USD/tấn (2040) theo kịch bản giá dầu 65 USD/thùng (Hình 3).

Căn cứ vào giá melamine tại khu vực Đông Nam Á (đã bao gồm chi phí vận chuyển) do Nexant dự báo trong giai đoạn 2019 - 2040 và chi phí vận chuyển tham khảo của Logivan từ cổng Nhà máy Đạm Cà Mau đến cảng Cát Lái (Tp. Hồ Chí Minh) thời điểm tháng 10/2019 là 14,06 USD/tấn, giá melamine tại cổng Nhà máy Đạm Cà Mau được dự báo ở mức 1.515 USD/tấn (2025), 1.949 USD/tấn (2030), 2.525 USD/tấn (2035) và 2.361 USD/tấn (2040). Dự báo giá melamine tại cổng Nhà máy Đạm Cà Mau theo kịch bản giá dầu 65 USD/thùng được thể hiện ở Hình 4.

\subsection{Nguyên liệu}

Trong nghiên cứu này, nguyên liệu chính để sản xuất melamine là nguồn urea từ phân xưởng urea của Nhà máy Đạm Cà Mau. Do yêu cầu về giới hạn nồng độ các tạp chất trong nguyên liệu sản xuất như formaldehyde $(<0,1 \%$ khối lượng) và biuret (<5\% khối lượng), dịch urea làm nguyên liệu cho sản xuất melamine sẽ được trích tại vị trí sau cụm phân hủy thấp áp của xưởng urea. Tính chất dịch urea được thể hiện trong Bảng 3.

\section{Công nghệ và giải pháp kỹ thuật}

Các nhà máy sản xuất melamine thường được xây dựng tích hợp với các nhà máy sản xuất phân đạm nhằm mục đích tuần hoàn 2 cấu tử ammonia và carbon dioxide có trong sản phẩm phụ của quá trình sản xuất melamine trở về làm nguyên liệu cho sản xuất phân đạm. Việc tích hợp nhà máy sản xuất melamine với tổ hợp sản xuất urea làm giảm lượng tiêu hao riêng của nguyên liệu urea cho quá trình tổng hợp melamine, qua đó giúp nâng cao hiệu suất chuyển hóa và tăng hiệu quả kinh tế cho các dây chuyền công nghệ. Sơ đồ tổng quát phản ứng tổng hợp melamine như Hình 5.

Mỗi công nghệ sản xuất melamine từ urea có một đặc điểm riêng nhưng nhìn chung điểm khác biệt lớn nhất giữa các công nghệ là điều kiện phản ứng (áp suất cao/thấp). Đầu tiên, urea được gia nhiệt và phân hủy thành acid isocyanic và ammonia. Sau đó acid isocyanic được chuyển hóa thành melamine và carbon dioxide. Công nghệ thấp áp tổng hợp melamine sử dụng chất xúc tác trong điều kiện áp suất thấp (8 - 10 bar). Công nghệ này được ứng dụng trong công nghiệp với dây chuyền đầu tiên vào năm 1967. Công nghệ tổng hợp melamine áp suất cao được nghiên cứu và ứng dụng trong công nghiệp lần đầu vào năm 1963, sớm hơn công nghệ áp suất thấp. Công nghệ cao áp hoạt động trong điều kiện áp suất cao (70 - 90 bar) nhằm mục đích tăng hiệu quả của quá trình phản ứng. So với công nghệ thấp áp, công nghệ cao áp có các ưu điểm sau:

- Chỉ số vận hành dây chuyền cao, yêu cầu bảo trì thấp do không sử dụng xúc tác (không cần thay xúc tác định kỳ); 
- Dây chuyền có độ linh hoạt cao, thao tác vận hành (khởi động và dừng) dễ dàng. Có khả năng thay đổi công suất lớn theo yêu cầu sản xuất;

- Điều kiện hoạt động ở áp suất cao thích hợp cho việc tích hợp với phân xưởng sản xuất urea. Các dòng nguyên liệu và dòng hồi lưu khi đấu nối không cần lắp đặt bơm/máy nén bổ sung [9].

- Sản phẩm chính (melamine) đồng nhất có chất lượng cao và ổn định, sản phẩm phụ (hỗn hợp khí amoniac và $\mathrm{CO}_{2}$ ) thích hợp để tái sản xuất urea.

Hiện nay, công nghệ melamine đã được thương mại hóa rộng rãi trên toàn thế giới. Một số nhà bản quyền công nghệ tiêu biểu gồm Eurotecnica (Italy), Casale (Austria), BASF (Đức), Lurgi (Đức)... Trong đó, Eurotecnica đã cấp bản quyền công nghệ cho hơn 20 nhà máy sản xuất melamine trên toàn thế giới và có kinh nghiệm tích hợp nhà máy sản xuất melamine với nhà máy đạm xây dựng theo công nghệ bản quyền của Saipem Snamprogetti, Stamicarbon, Toyo... Casale cũng đã cấp bản quyền công nghệ cho 4 nhà máy melamine đi vào vận hành thương mại trên thế giới.

Sơ đồ công nghệ sản xuất melamine theo bản quyền của Eurotecnica được trình bày ở Hình 6 [4].
Quá trình tổng hợp melamine xảy ra ở pha lỏng dưới điều kiện áp suất cao, không sử dụng xúc tác, gồm các khu vực chính sau:

- Khu vực cô đặc nguyên liệu và chuyển hóa:

Urea lỏng từ xưởng urea được đưa vào thiết bị cô đặc. Dòng urea sau khi được cô đặc đến nông độ 99,7\% sẽ được chuyển qua thiết bị phản ứng (R1) để sản xuất melamine. Nước ngưng thu hồi được từ thiết bị cô đặc được đưa đến phân xưởng xử lý nước thải của nhà máy đạm. Dòng urea nóng chảy từ xưởng cô đặc $\left(145^{\circ} \mathrm{C}\right)$ được trộn lẫn với dòng $\mathrm{NH}_{3}$ đã được gia nhiệt $\left(450^{\circ} \mathrm{C}\right)$ rồi phân phối đều vào thiết bị phản ứng. Tại đây, melamine được tạo thành theo phản ứng tổng quát sau:

$$
6\left(\mathrm{NH}_{2}\right)_{2} \mathrm{CO} \rightarrow \mathrm{C}_{3} \mathrm{H}_{6} \mathrm{~N}_{6}+6 \mathrm{NH}_{3}+3 \mathrm{CO}_{2}
$$

Thiết bị phản ứng được gia nhiệt bằng muối nóng chảy, nhiệt độ của muối nóng chảy được kiểm soát trong khoảng $400-470^{\circ} \mathrm{C}$ nhằm đảm bảo duy trì nhiệt độ trong thiết bị phản ứng là $380^{\circ} \mathrm{C}$. Tại tầng trên cùng của thiết bị chuyển hóa, khí thải được tách ra khỏi dòng melamine nóng chảy rồi đi vào tháp làm mát (C1). Melamine nóng chảy được đưa qua thiết bị chuyển hóa cuối (R2), tại đây, $\mathrm{CO}_{2}$ hòa tan trong dòng melamine nóng chảy được loại bỏ nhờ dòng ammonia quá nhiệt.

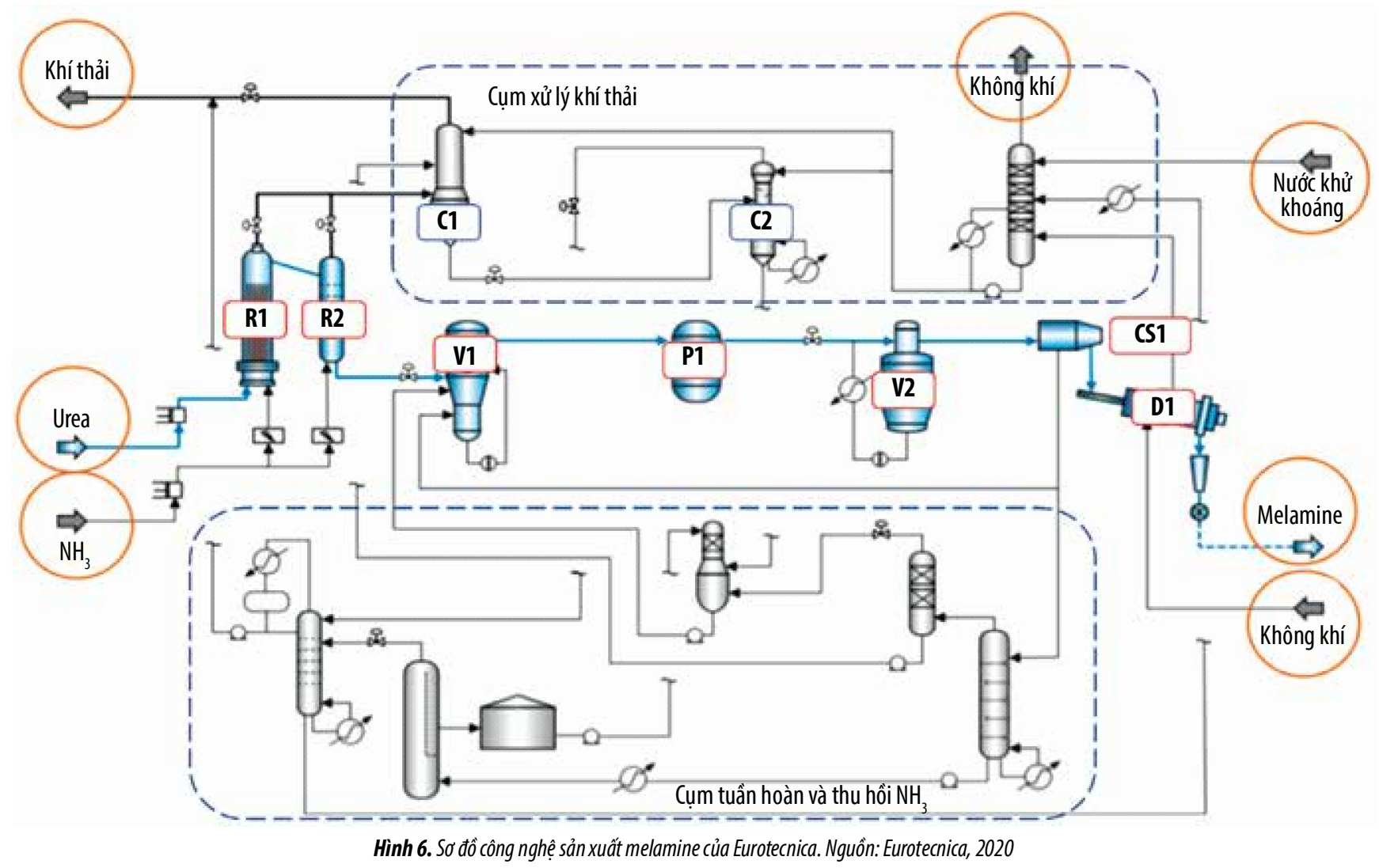


Ngoài ra, tại thiết bị chuyển hóa cuối (R2), việc kéo dài thời gian lưu và bổ sung dòng ammonia còn giúp tăng độ chuyển hóa của urea và các sản phẩm trung gian. Dòng khí ra khỏi đỉnh của thiết bị chuyển hóa cuối (R2) được trộn lẫn với dòng khí đi ra từ đỉnh thiết bị phản ứng (R1) rồi đi vào tháp làm mát (C1).

Melamine nóng chảy từ đáy thiết bị chuyển hóa cuối (R2) được đưa sang thiết bị hòa tan (V1). Tại đây, melamine được làm mát và hòa tan trong dung dịch giàu ammonia rồi được bơm qua khu tinh chế. Bơm tuần hoàn được lắp đặt ở đáy thiết bị hòa tan (V1) nhằm tăng cường khả năng hòa tan của melamine vào dung dịch giàu ammonia.

- Khu vực xử lý khí thải:

Khí thải chứa ammonia, carbon dioxide và một lượng nhỏ hơi melamine bị cuốn theo được đưa đến tháp làm mát (C1). Tại đây, hơi melamine được thu hồi, khí đi ra từ đỉnh tháp (C1) không còn chứa melamine, có nhiệt độ 158 ${ }^{\circ} \mathrm{C}$ và áp suất 23,5 bar được hồi lưu lại xưởng urea của nhà máy đạm. Dung dịch thu được ở đáy tháp (C1) chứa ammonia, carbon dioxide và melamine hòa tan được đưa đến tháp tách (C2) để tách loại phần lớn carbon dioxide và ammonia. Dòng khí từ đỉnh được đưa đến cụm tuần hoàn và thu hồi ammonia rồi quay lại xưởng urea.

- Khu vực tinh chế melamine:

Melamine thô hòa tan trong nước giàu ammonia từ đáy của thiết bị hòa tan V1 được đưa qua cụm tinh chế (P1), gồm 2 phần chính: thiết bị lọc cho phép loại bỏ các tạp chất không hòa tan, và than hoạt tính cho phép loại bỏ các tạp chất hòa tan trong dòng melamine.

- Khu vực kết tinh và sấy:

Thiết bị kết tinh (V2) làm việc ở nhiệt độ 42 - $45^{\circ} \mathrm{C}$ và áp suất khí quyển. Dòng melamine sau khi ra khỏi thiết bị kết tinh được bơm đến máy ly tâm (CS1). Tại đây, tinh thể melamine được tách ra với độ ẩm khoảng 10\% khối lượng, tiếp tục được đưa đến thiết bị sấy (D1) để giảm hàm lượng ẩm. Sản phẩm melamine thu được có độ ẩm không quá 0,1\% khối lượng.

Tiêu hao nguyên liệu và phụ trợ điển hình cho sản xuất melamine được trình bày ở Bảng 4.

Nhà máy sản xuất melamine mới và Nhà máy Đạm Cà Mau sẽ được tích hợp nguyên liệu, phụ trợ tiện ích và các dòng công nghệ trung gian [9]. Phương án tích hợp tiêu biểu được mô tả như sau:

- Nguyên liệu dịch urea: từ xưởng urea của Nhà máy Đạm Cà Mau có nồng độ khoảng 70\% khối lượng được chuyển sang nhà máy sản xuất melamine.

- Dòng ammonia: từ xưởng urea của Nhà máy Đạm Cà Mau cung cấp cho nhà máy sản xuất melamine. Ammonia đóng vai trò tạo môi trường phản ứng, không tham gia vào quá trình phản ứng và sẽ được hồi lưu theo dòng dịch carbamate về xưởng urea.

- Melamine offgas: dòng khí này được ngứng tụ hoàn toàn tại nhà máy sản xuất melamine, sau đó cùng với dòng dịch carbamate quay về khu vực tổng hợp urea.

- Nước công nghệ: từ nhà máy sản xuất melamine được chuyển tới xưởng urea, trộn lẫn với dòng nước công nghệ từ quá trình cô đặc nồng độ urea tại xưởng urea hiện hữu, sau đó được xử lý tại trạm xử lý nước thải của xưởng urea.

Công nghệ sản xuất melamine của Eurotecnica không sử dụng hóa chất và/hoặc chất xúc tác cho công đoạn phản ứng cũng như tinh chế sản phẩm. Do đó, đem đến lợi thế là tránh phát sinh và thải bỏ nguồn thải ô nhiễm dạng lỏng và rắn [10].

Nhằm mục đích xem xét khả năng tích hợp của nhà

Bảng 4. Tiêu hao nguyên liệu và phu trợ sản xuất melamine

\begin{tabular}{|c|c|c|}
\hline Thông số & Lượng tiêu hao & Đơn vị tính \\
\hline \multicolumn{3}{|l|}{ Nguyên liệu } \\
\hline Urea (Net, 100\%) & 1,4286 & Tấn/tấn \\
\hline \multicolumn{3}{|l|}{ Phụ trợ } \\
\hline Điện & 450 & kWh/tấn \\
\hline Nước làm mát (hồi lưu) & 387 & $\mathrm{~m}^{3} / \mathrm{tấn}$ \\
\hline Nhiên liệu & 1,69 & Gcal/tấn \\
\hline Hơi cao áp & 4,62 & Tấn/tấn \\
\hline Khí nitơ & 6 & $\mathrm{Nm}^{3} /$ tấn \\
\hline Khí nén & 80 & $\mathrm{Nm}^{3} / \mathrm{tấn}$ \\
\hline Không khí hệ thống vận chuyển & 476 & $\mathrm{Nm}^{3} /$ tấn \\
\hline Năng lượng xử lý các dòng hồi lưu & 3,164 & Gcal/tấn \\
\hline
\end{tabular}

Nguồn:VPI 
máy sản xuất melamine với Nhà máy Đạm Cà Mau, VPI đã kết hợp với đội ngũ kỹ thuật của nhà máy cùng với các nhà bản quyền công nghệ để đánh giá sơ bộ thiết bị hiện hữu. Kết quả đánh giá như sau:

- Các máy bơm carbamate: Dịch giàu carbamate thu được từ nhà máy sản xuất melamine được hồi lưu lại khu vực tổng hợp urea bằng máy bơm carbamate hiện hữu. Lưu lượng dòng lỏng sẽ tăng hơn khoảng 50\% so với lưu lượng hiện tại. Do đó, cần đánh giá lại khả năng hoạt động của bơm với nhà sản xuất bơm ở giai đoạn sau.

- Dòng carbamate hồi lưu đến vòng tổng hợp cao áp tăng lên do sự tích hợp của nhà máy sản xuất melamine. Các điều kiện hoạt động của đầu phun carbamate hiện tại vẫn được duy trì, dòng carbamate mới bổ sung được bơm trực tiếp đến thiết bị phản ứng tổng hợp urea theo đường mới riêng biệt.

- Thiết bị phản ứng tổng hợp urea: Các điều kiện vận hành công nghệ hiện hữu có một số thay đổi nhỏ do sự gia tăng lưu lượng carbamate và giảm thời gian lưu trong thiết bị phản ứng. Thể tích thiết bị phản ứng tổng hợp urea vẫn phù hợp để chuyển đổi lượng carbamate bổ sung thành urea mà không cần phải cải hoán thiết bị phản ứng.

- Thiết bị ngưng tụ carbamate cao áp và stripper: Phạm vi hoạt động của các thiết bị này (theo thiết kế điển hình của Snamprogetti/Saipem) cho phép thay đổi trong khoảng $+20 \%$, do đó, các thiết bị này có thể vận hành phù hợp sau khi công suất tăng lên mà không cần phải cải hoán.

Trong các bước triển khai tiếp theo (báo cáo nghiên cứu khả thi, thiết kế kỹ thuật tổng thể), đánh giá chi tiết về khả năng tích hợp nhà máy sản xuất melamine với Nhà máy Đạm Cà Mau sẽ được thực hiện.

\section{4. Đánh giá dự án sản xuất melamine}

\subsection{Quy mô công suất}

Quy mô công suất của nhà máy sản xuất melamine được đề xuất dựa trên các tiêu chí sau:

- Khả năng tiêu thụ sản phẩm ở thị trường trong nước: Dự báo nhu cầu thị trường melamine nội địa năm 2025 đạt hơn 40 nghìn tấn/năm. Với mức công suất lựa chọn 40 nghìn tấn/năm, sản phẩm melamine có thể được định hướng tiêu thụ hoàn toàn trong nước. Dự kiến dự án sẽ đi vào vận hành từ năm 2027, khi giá melamine vẫn đang ở chu kỳ tăng [11] và đáp ứng khoảng $80 \%$ nhu cầu trong nước vào năm 2030. Trong trường hợp không xét đến nhu cầu tiêu thụ của các công ty có đối tác, công ty mẹ ở nước ngoài sản xuất melamine thì quy mô thị trường còn lại khoảng 70\% tổng nhu cầu cả nước. Như vậy, hướng tiêu thụ cho dự án phải xem xét đến phương án tiêu thụ trong nước $70 \%$ và xuất khẩu $30 \%$. Một số thị trường xuất khẩu tiềm năng gồm: Ấn Độ, Malaysia, Indonesia và Thái Lan.

- Dãy công suất thương mại hóa và mức công suất tối thiểu theo khuyến cáo từ các nhà bản quyền: Dãy công suất thương mại dao động từ $15-80$ nghìn tấn/năm. Tuy nhiên, để đảm bảo hiệu quả kinh tế khi vận hành nhà máy, các nhà bản quyền cung cấp công nghệ sản xuất melamine như Eurotechnica và Casale đều khuyến cáo không nên xây dựng dự án có công suất dưới 40 nghìn tấn/năm.

- Khả năng kết nối với Nhà máy Đạm Cà Mau hiện hữu: Phân xưởng melamine sẽ sử dụng nguyên liệu chính là dịch urea từ Nhà máy Đạm Cà Mau. Hiện nay, phân xưởng sản xuất phân bón phức hợp đi vào hoạt động đã nhận khoảng $12 \%$ lượng dịch urea $96 \%$ mà xưởng urea có thể sản xuất. Do đó, lượng dịch urea tối đa cấp được làm nguyên liệu cho xưởng melamine còn khoảng 10\% tổng sản lượng dịch urea (khoảng 10 tấn/giờ). Lượng dịch urea này có thể sản xuất tương ứng được hơn 50 nghìn tấn/ năm melamine. Bên cạnh đó, các dòng công nghệ và các dòng phụ trợ tuần hoàn từ phân xưởng melamine về lại xưởng urea của Nhà máy Đạm Cà Mau hiện hữu sẽ tăng tải hệ thống Nhà máy Đạm Cà Mau. Nhà máy sản xuất melamine cũng sẽ sử dụng chung một số tiện ích như hơi, nước làm mát, nhiên liệu, khí điều khiển... từ nhà máy. Do đó, để đảm bảo sự vận hành của nhà máy sản xuất melamine không ảnh hưởng đến vận hành ổn định của nhà máy hiện hữu, mức công suất sản xuất melamine là 40 nghìn tấn/năm sẽ được xem xét lựa chọn.

Như vậy, dựa trên các yếu tố nhu cầu thị trường, kinh nghiệm thương mại hóa các nhà máy sản xuất melamine trên thế giới cũng như khả năng kết nối với Nhà máy Đạm Cà Mau, mức công suất được đề xuất cho phân xưởng sản xuất melamine là 40 nghìn tấn/năm.

\subsection{Tiến độ thực hiện dự án}

Với phân tích ở phần thị trường, Dự án sẽ được xem xét đầu tư ở thời điểm thích hợp khi quy mô thị trường đủ lớn, phù hợp với công suất tối thiểu theo yêu cầu của nhà bản quyền công nghệ. Qua đó, thời điểm dự án đi vào vận hành được đề xuất từ năm 2027 (năm melamine có chu kỳ giá cao).

\section{3. Đề xuất địa điểm}

Diện tích dự kiến của nhà máy sản xuất melamine là $7.200 \mathrm{~m}^{2}$, chưa bao gồm nhà kho chứa sản phẩm. Khi tích 
hợp nhà máy sản xuất melamine với nhà máy đạm hiện hữu, cần xem xét vị trí đặt gần xưởng urea để việc kết nối giữa 2 nhà máy được thuận lợi, giảm chi phí đầu tư. Tuy nhiên, khảo sát Nhà máy Đạm Cà Mau hiện hữu cho thấy hiện tại không có khu đất trống xung quanh xưởng urea. Do đó, nhà máy sản xuất melamine sẽ được định hướng xây dựng tại khu đất dự phòng dành cho mở rộng trong Nhà máy Đạm Cà Mau.

Bảng 5. Tổng mức đầu tư nhà máy sản xuất melamine

\begin{tabular}{|c|c|c|c|}
\hline TT & Các chi phí & Giá trị (tỷ đồng) & Cơ sở \\
\hline 1 & Chi phí xây dựng & 861,51 & Theo kinh nghiệm \\
\hline 2 & Chi phí thiết bị & $2.887,02$ & VPI tổng hợp \\
\hline 3 & Chi phí quản lý dự án & 46,56 & \multirow{2}{*}{$\begin{array}{c}\text { Theo Quyết định số 79/QĐ- } \\
\text { BXD ngày 15/2/2017 }\end{array}$} \\
\hline 4 & Chi phí tư vấn đâu tư xây dựng & 414,24 & \\
\hline 5 & Chi phí khác & 89,45 & Theo kinh nghiệm \\
\hline 6 & Chi phí dự phòng (15\%) & 644,82 & Theo kinh nghiệm \\
\hline 7 & Dự phòng trượt giá ngoại tệ (5\%) & 215,00 & Theo kinh nghiệm \\
\hline 8 & Tổng mức đâuu tư cố định & $5.158,60$ & \\
\hline 9 & Thuế VAT (10\%) & 516,67 & \\
\hline 10 & Lãi vay trong quá trình xây dựng & 554,67 & \\
\hline 11 & Vốn lưu động năm đầu & 78,44 & \\
\hline 12 & $\begin{array}{l}\text { Tổng mức đầu tư (bao gồm thuế VAT, lãi vay và vốn lưu động } \\
\text { năm đấu) }\end{array}$ & $6.308,38$ & \\
\hline
\end{tabular}

Bảng 6. Các thông số giả định của dự án đầu tư nhà máy sản xuất melamine

\begin{tabular}{|c|c|c|c|}
\hline TT & Các thông số giả định & Đơn vị & Nhà máy sản xuất melamine \\
\hline 1 & Thời gian xây dựng & Tháng & 28 \\
\hline \multirow[t]{2}{*}{2} & Thời gian vận hành & Năm & $20(2027-2046)$ \\
\hline & Số ngày vận hành & Ngày/năm & 333 \\
\hline \multirow[t]{2}{*}{3} & Công suất & Tấn/ngày & 120 \\
\hline & & Tấn/giờ & 5 \\
\hline \multirow[t]{4}{*}{4} & Tỷ lệ vận hành & $\%$ & \\
\hline & Năm đâu tiên & $\%$ & 80 \\
\hline & Năm thứ 2 & $\%$ & 90 \\
\hline & Từ năm thứ 3 & $\%$ & 100 \\
\hline \multirow[t]{4}{*}{5} & Thời gian khấu hao (tuyến tính) & Năm & \\
\hline & Thiết bi! & Năm & 10 \\
\hline & Xây dựng & Năm & 12 \\
\hline & Khác & Năm & 5 \\
\hline \multirow[t]{10}{*}{6} & Nhân công & Người & 45 \\
\hline & Quản lý & Người & 1 \\
\hline & Kỹ sư & Người & 1 \\
\hline & Giám sát & Người & 5 \\
\hline & Điêu khiển & Người & 10 \\
\hline & Vận hành & Người & 10 \\
\hline & Kiểm soát chất lượng & Người & 2 \\
\hline & Cơđiện & Người & 8 \\
\hline & An toàn & Người & 4 \\
\hline & Khác & Người & 4 \\
\hline 7 & Vốn chủ sở hữu & $\%$ & 30 \\
\hline 8 & Vốn vay & $\%$ & 70 \\
\hline 9 & Thời gian trả nợ & Năm & 8 năm, ân hạn trong thời gian xây dựng \\
\hline 10 & Lãi vay VNĐ & $\%$ & 11 \\
\hline \multirow[t]{4}{*}{11} & Thuế thu nhập doanh nghiệp & $\%$ & $\begin{array}{l}\text { Nghị định số 218/2013/NĐ-CP } \\
\text { của Chính phủ }\end{array}$ \\
\hline & Năm 2024 & & \\
\hline & Giai đoạn 2025 - 2026 & $\% /$ năm & 10 \\
\hline & Giai đoạn 2027 - 2044 & \%/năm & 20 \\
\hline 12 & Tỷ suất chiết khấu & $\%$ & 10 \\
\hline 13 & Tỷ giá (2020) & VND/USD & 23.835 \\
\hline 14 & Kịch bản giá dầu cơ sở & USD/thùng & 65 \\
\hline
\end{tabular}


Bảng 7. Kết quả tính toán các chỉ tiêu hiệu quả kinh tế của dự án

\begin{tabular}{|c|c|c|c|}
\hline TT & Các kết quả tính toán & Đơn vị & Dựán \\
\hline 1 & Doanh thu & Tỷ đồng & 69.110 \\
\hline \multirow[t]{3}{*}{2} & Chi phí & & \\
\hline & Chi phí đầu tư & Tỷ đồng & 5.158 \\
\hline & Chi phí sản xuất & Tỷ đồng & 40.858 \\
\hline \multirow[t]{4}{*}{3} & Hiệu quả kinh tế toàn dự án & & \\
\hline & NPV@10\% & Tỷ đồng & 1.884 \\
\hline & IRR & $\%$ & 17,2 \\
\hline & Thời gian hoàn vốn & & 5 năm 9 tháng \\
\hline \multirow[t]{3}{*}{4} & Hiệu quả kinh tế theo quan điểm chủ đầu tư & & \\
\hline & NPV@12\% & Tỷ VNĐ & 2.569 \\
\hline & IRR & $\%$ & 33,5 \\
\hline
\end{tabular}

\subsection{Chi phí vận chuyển}

Chi phí vận chuyển sản phẩm melamine từ Cà Mau đến hộ tiêu thụ tiềm năng là chi phí vận chuyển nội địa. Tham khảo giá vận chuyển của Logivan thì chi phí vận chuyển melamine từ Cà Mau đến cảng Cát Lái (Tp. Hồ Chí Minh) để phân phối cho các khách hàng khác khoảng 14,06 USD/tấn, chiếm $1 \%$ giá tại cổng. Trong khi đó, các nhà cung cấp melamine hiện tại chủ yếu ở nước ngoài (Trung Quốc chiếm hơn 95\%). Ước tính theo dữ liệu của ICIS, chi phí vận chuyển melamine từ Trung Quốc về Việt Nam khoảng 160 - 170 USD/tấn. Như vậy, nếu cùng một mức giá FOB như nhau thì chi phí vận chuyển từ nước ngoài về Việt Nam sẽ cao hơn so với chi phí vận chuyển trong nước.

\subsection{Tổng mức đầu tưvà̀ hiệu quả kinh tế}

\subsubsection{Tổng mức đâu tư}

Tổng mức đầu tư của dự án được lập dựa trên tính toán của VPI và đơn vị thiết kế, các định mức theo Thông tư số 09/2019/TT-BXD ngày 26/12/2019 về việc Hướng dẫn lập và quản lý chi phí đầu tư xây dựng công trình và Quyết định số 79/QĐ-BXD ngày 15/2/2017 công bố định mức chi phí quản lý dự án và tư vấn đầu tư xây dựng, bao gồm các chi phí: chi phí xây dựng, chi phí thiết bị, chi phí khác, chi phí quản lý dự án, chi phí tư vấn đầu tư xây dựng và chi phí dự phòng.

Chi tiết tổng mức đầu tư cho dựán nhà máy sản xuất melamine được thể hiện chi tiết theo Bảng 5.

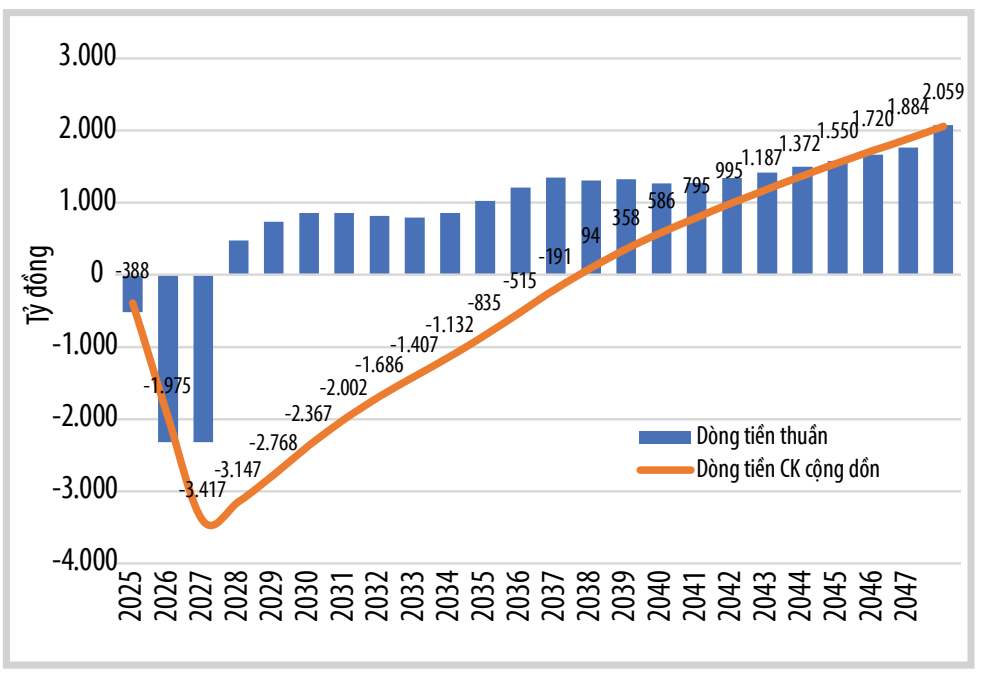

Hình 7. Dòng tiên thuần toàn dự án đâu tư thêm xưởng sản xuất melamine.

\subsubsection{Hiệu quả kinh tế}

Hiệu quả kinh tế của dự án được tính toán dựa trên các thông số giả định trong Bảng 6 .

Hiệu quả kinh tế của dự án sản xuất melamine được thể hiện trong Bảng 7.

Kết quả tính toán cho thấy dự án sản xuất melamine đạt hiệu quả kinh tế với IRR là $17,2 \%$ (cao hơn tỷ suất chiết khấu 10\%) và NPV@10\% toàn dự án đạt 1.884 tỷ đồng.

Về tổng thể, dự án sản xuất melamine đem lại hiệu quả kinh tế cho Nhà máy Đạm Cà Mau. Kết quả tính toán dòng tiền thuần cho thấy dự án thu lãi ngay từ năm đầu tiên đi vào vận hành (năm 2027). Tuy nhiên, do nhu cầu vốn đầu tư của dự án khá lớn nên đến năm 2038 dự án mới hòa vốn tại thời điểm dòng tiền cộng dồn bắt đầu dương (Hình 7).

Với kết quả phân tích độ nhạy của dự án theo công suất trình bày ở Hình 8 , dự án đầu tư thêm nhà máy sản xuất melamine mang lại hiệu quả tăng thêm cho Nhà máy Đạm Cà Mau, kể cả khi công suất sản xuất giảm còn $70 \%$ công suất thiết kế. 


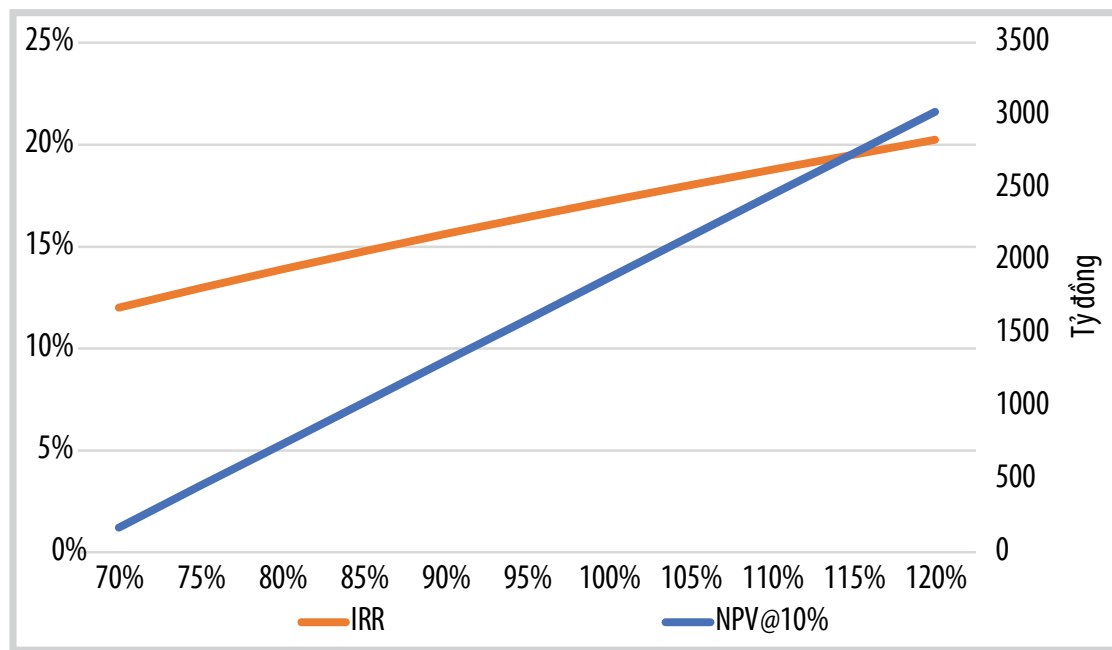

Hình 8. Độ nhạy chỉ tiêu NPV@10\% và IRR của dựán theo công suất sản xuất.

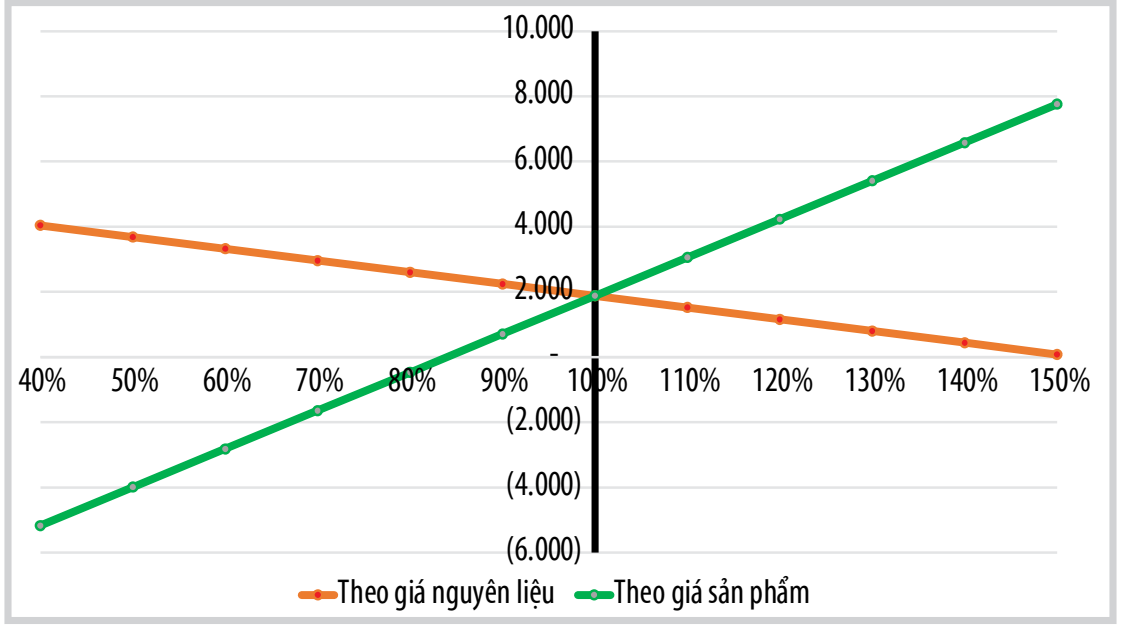

Hình 9. Độ nhạy chỉ tiêu NPV@10\% dự án theo giá nguyên liệu và sản phẩm.

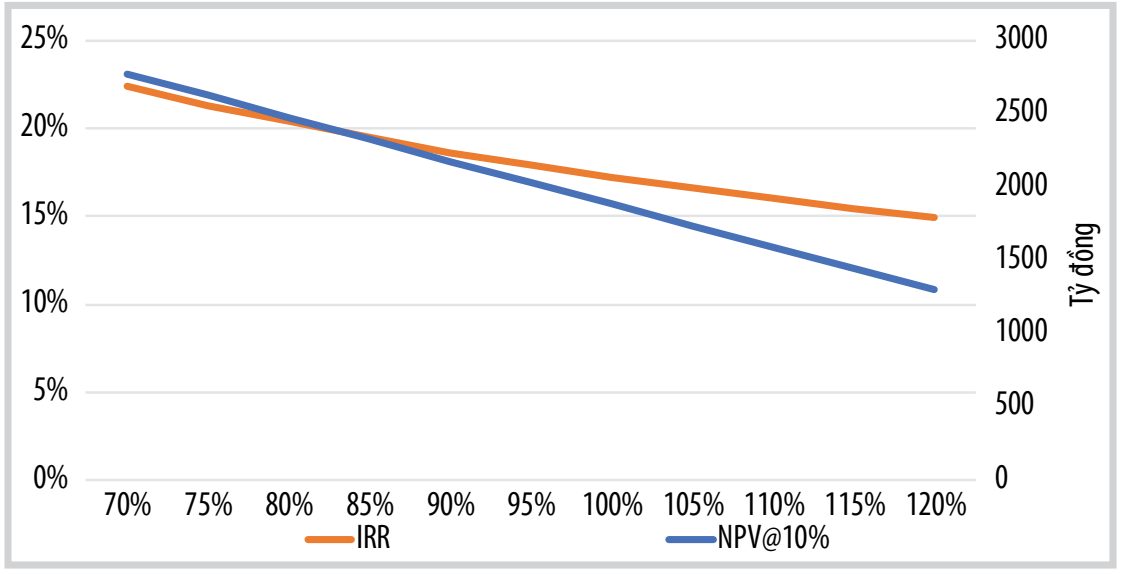

Hình 10. Độ nhạy chỉ tiêu NPV@10\% và IRR của dự án theo tổng múc đầu tư.

Bảng 8. Ảnh hưởng của tiến độ vận hành đến hiệu quả của dựán

\begin{tabular}{|c|c|c|c|}
\hline TT & Kịch bản & NPV@10\% & IRR (\%) \\
\hline 1 & Vận hành năm 2025 & 1.688 & 14,4 \\
\hline 2 & Vận hành năm 2026 & 1.807 & 14,8 \\
\hline 3 & Vận hành năm 2027 & 1.884 & 17,2 \\
\hline 4 & Vận hành năm 2028 & 1.896 & 15,8 \\
\hline 5 & Vận hành năm 2029 & 1.879 & 16,0 \\
\hline
\end{tabular}

Đối với dự án sản xuất melamine, giá sản phẩm ảnh hưởng nhiều nhất đến hiệu quả kinh tế của dự án. Khi giá sản phẩm giảm 40\%, NPV giảm khoảng 4.000 tỷ đồng. Khi tăng 40\% giá sản phẩm, NPV tăng xấp xỉ 4.500 tỷ đồng. Khi giảm 40\% giá nguyên liệu, NPV tăng khoảng 1.200 tỷ đồng. NPV bắt đầu âm khi tăng giá nguyên liệu tới 50\% (Hình 9). Chi phí đầu tư cũng ảnh hưởng nhưng không đáng kể đến hiệu quả kinh tế của dự án, cụ thể tổng mức đâu tư tăng thêm $20 \%$ thì IRR của dự án vẫn đạt 15\% (Hình 10), NPV bắt đầu âm khi tăng tổng mức đầu tư tới 50\%.

Trong bối cảnh suy giảm sản lượng khí và thay đổi giá khí hiện nay, dự án melamine nên được xem xét đưa vào đầu tư sớm để nâng cao năng lực cạnh tranh, thích ứng với sự biến động thị trường của Nhà máy Đạm Cà Mau. Để đánh giá ảnh hưởng của tiến độ vận hành đến hiệu quả kinh tế của dự án, nhóm tác giả đã tính toán hiệu quả kinh tế của 5 kịch bản có năm vận hành khác nhau tính từ năm 2025 với thời gian xây dựng là 28 tháng. Kết quả tính toán ở Bảng 8 cho thấy các kịch bản đều đem lại hiệu quả về kinh tế cho dự án. Trong đó, dự án đi vào vận hành tối ưu là năm 2027 với IRR cao nhất đạt 17,2\% và NPV@10\% tương ứng là 1.884 tỷ đồng.

\section{Kết luận}

Dự báo nhu cầu melamine của Việt Nam đạt khoảng 40 nghìn tấn/ năm vào năm 2025 và sẽ tiếp tục tăng trưởng 5,5\%/năm đến năm 2040. Với đánh giá sơ bộ về mặt công nghệ và thị trường, dự án sản xuất melamine từ urea của Nhà máy Đạm Cà Mau được đềxuất với quy mô công suất 40 nghìn tấn/năm và dự kiến đi vào hoạt động vào năm 2027 để nắm bắt chu kỳ tăng giá của melamine và đáp ứng khoảng $80 \%$ nhu cầu trong nước vào năm 2030. 
Với tổng mức đầu tư (đã bao gồm thuế, lãi vay và vốn lưu động năm đầu) khoảng 6.308 tỷ đồng, dự án có hiệu quả với IRR = 17,2\%, NPV@10\% là khoảng 1.884 tỷ đồng và thời gian thu hồi vốn khoảng 5 năm 9 tháng. Kết quả cho thấy tiềm năng của dự án và cần được đánh giá chi tiết ở các bước tiếp theo.

\section{Tài liệu tham khảo}

[1] IHS, Melamine - Chemical Economics Handbook, 2014.

[2] Henan Xinlianxin Chemicals Group Co., Ltd., "Company profile", 2018. [Online]. Available: https:// xlxchemicals.com/index/home.

[3] Xinjiang Yihua Chemical Industry Co., Ltd., "Company profile". [Online]. Available: https:// xinjiangyihua.lookchem.com/.

[4] Eurotechnica Contractors and Engineers S.p., Euromel melamine technology, 2020.

[5] Công ty CP Phân bón Dầu khí Cà Mau, "Cột mốc 7 triệu tấn sản phẩm và hành trình nỗ lực của Đạm Cà Mau", $14 / 9 / 2020$.
[6] Công ty CP gỗ MDF VRG Quảng Trị,, "Báo cáo thường niên năm 2019", 2020.

[7] Nguyễn Văn Định và Phạm Văn Tiến, "Nghiên cứu sản xuất keo dán gỗ thay thế keo nhập khẩu phục vụ công nghiệp chế biến lâm sản", Trung tâm Nghiên cứu và Chuyển giao công nghệ Công nghiệp rừng.

[8] Tổng cục Hải quan, "Số liệu xuất nhập khẩu sản phẩm melamine", 2019.

[9] G.Di Carlo, "Melding melamine and urea", World fertilizer, 2020. [Online]. Available: https://www.casale. ch/downloads/melamine/more-melamine/33-meldingmelamine-and-urea/file.

[10] Eurotecnica, "Total-zero pollution". [Online]. Available: https://www.eurotecnica.it/en/total-zeropollution.html.

[11] Nexant, "Petroleum and petrochemical pricing report", 2019.

\title{
PRELIMINARY EVALUATION OF POSSIBLE MELAMINE PRODUCTION USING UREA SOLUTION FROM CA MAU FERTILIZER PLANT AS A FEEDSTOCK
}

\author{
Vo Thi Thuong, Tran Vinh Loc, Le Duong Hai, Nguyen Thi Mai Le, Pham Thu Trang, Nguyen Trung Duc \\ Nguyen Manh Huan, Nguyen Anh Thu Hang, Huynh Minh Thuan \\ Vietnam Petroleum Institute \\ Email: thuongvt.pvpro@vpi.pvn.vn
}

\section{Summary}

This paper analyses the possibility for melamine production from urea solution of Ca Mau Fertilizer Plant in terms of feedstock, market, technology and economic efficiency. Vietnam is currently importing melamine to meet its domestic demand, which is forecasted to be around 40 thousand tons per year by 2025 and continue to increase by about 5.5\% per year. The melamine production project using urea solution from Ca Mau Fertilizer Plant as a feedstock with a capacity of 40 thousand tons per year is proposed to go into operation in 2027. The results show that with an estimated total investment cost of VND 6,308 billion, the project's IRR will be around 17.2\% and its NPV@10\% will beVND 1,884 billion. The total payback period of the project will be 5 years and 9 months. This reveals that melamine can be considered a potential product for consideration of future investment.

Key words: Melamine, urea feedstock, product diversification, Ca Mau Fertilizer Plant. 